sound down to the very bottom of the cavity posteriorly, and respiration can be heard, mixed, indeed, with coarse crepitation to the same depth; the lungs are, like the legs, anasarcous; I do not think there is much, if any, liquid in the pericardium; wheezing and snoring respiration is audible throughout the chest; there is no albumen in this man's urine; it is not a case of renal dropsy; his lungs are probably emphysematous. Diseases of the lungs and of the heart mutually influence each other; whether the lungs were in this case primarily affected, or the heart, the present symptoms and the ascertained history of the patient do not enable us to determine. Venesection to the amount of ten ounces was performed on the evening of his admission; the blood did not exhibit any mark of inflammation. The case is a very unpromising one however. I am giving him diuretics.

Richard Hartley, aged forty-two, is a house-painter ; he is the third house-painter I have admitted within the last month. The two former came in, you will recollect, with colica pictonum. This man presents you with another common effect of the poison of lead, which I alluded to when noticing those cases. He has "dropped wrists"-lead palsy; great debility, and imperfect paralysis of the extensor or muscles of the hands and fingers; the wrists have been more or less weak for the last four or five years; this is a curious consequence of the slow introduction of lead into the system. His occupation as a painter indicates that cause, and as a confirmation of its being the cause, we have the slight edging of blue on his gums ; these sufficiently stamp the palsy as depending on the introduction of the poison of lead. With this local paralysis there is also mixed up a degree of rheumatism, and this must be the first object of our treatment. It is a matter of regret that workmen who are exposed to this source of disease, whereby so many are permanently crippled, do not adopt Liebig's hint of drinking habitually what he calls " sulphuric lemonade." I see in this day's " Lancet," that this preventive has been tried in a large white lead manufactory at Birmingham, with remarkable success. The poisonous carbonate of lead is converted into an insoluble, and therefore harmless, sulphate.

James Mac Gouran is aged forty-four, and entered with head symptoms. A fortnight since he had a "fit," which, by the description given of it, appears to have been epileptic. He has had several similar attacks since, and is still stupid, confused, and somewhat incoherent, in consequence of the last. $\mathrm{He}$ complains of headache and giddiness, and has been intemperate. There is an episode in his history, which may, or may not, connect itself with his present state. Twenty years ago he was kicked on the forehead by a horse, and then had a succession of similar fits for several days; since that time till the present he had none; he is quite unconscious during the paroxysms, struggles a good deal, and on recovering remembers nothing of what has been passing. These, you know, are characteristics of epilepsy. He had been freely bled before admission; his pulse intermits occasionally. On the whole, I am inclined to think, that though the period of that injury is very distant, and any external symptoms of its effects were so long suspended, there has been all that time some mischief going on-some slow and insidious alteration in the skull.

On the two remaining men I have no remarks at present to offer. Daniel Hayes appears to be laboring under a very slight feverish cold. He suffers very little pain, has a quiet pulse, and urine natural; his skin also is cool, and I hope in the course of a week to dismiss him quite well. John Fruin is troubled with palpitation, but I can detect no organic disease of the heart. He also was subject to "strong fits," between the ages of seventeen and twenty; he is now thirty-two. Such is a very cursory account of our new patients. Next Saturday, Gentlemen, will be the day before Christmas-day; I cannot expect to see many of you here at that time. These lectures will, therefore, for the present at any rate, be suspended.

\section{STRANGULATED FEMORAL HERNIA.}

\section{TO THE EDITORS OF THE PROVINCIAL MEDICAL} JOURNAL.

Gentlemen, - Should the following case be deemed sufficiently interesting to your readers, it is at your service for insertion in the Provincial Medical Journal.

I am, Gentlemen, Your obedient servant, Johin Prankerd, Surgeon.

Langport, Somerset,

$$
\text { Dec. 21, } 1842 .
$$

On September 1, I was called on by a poor woman, who stated that a neighbour of hers had been very ill for five or six days, continually vomiting a very fœetid matter, and that her bowels had been confined for a similar period. I, of course, called on her soon after, and found my patient to be a single woman, by name Ann Abbott, aged sixty-three, accustomed to laborious work in her house and garden; she has been the subject of hernia three or four years, which she has hitherto reduced herself, and never wore a truss. Examination proved her to be laboring under strangulated femoral hernia of the right side, which had existed six days, the contents of the sac having protruded whilst lifting a heavy weight of potatoes ; I understood that she had almost immediately after been seized with vomiting, and had continued so incessantly ever since; the smallest quantity of liquid taken was rejected, accompanied by stercoraceous matter. The tumor was now exquisitely tender; the slightest touch seemed too much to be borne, the whole abdomen was tense and painful; the pulse very small, weak, and frequent, with general fever and restlessness. Under such circumstances the case appeared almost hopeless, and an operation to offer little chance of success. Finding I could not have recourse to the taxis, from the extreme pain, I placed her in a warm bath, where she was kept nearly an hour, until syncope partly occurred, when I attempted the reduction, but the great pain obliged me to desist, and my efforts failed in reducing the tumor. Glysters were administered, but returned unaltered; and opium was rejected. Desiring a cold application should be applied to the tumor, I left to obtain some assistance to perform the operation, if on consultation it was deemed desirable. On my way home, I was summoned to a pressing case of midwifery, which kept 
me engaged several hours, so that I did not return to my first patient until full eight hours after having left her. On my arrival, I found things much in the same position, except more fatigue and disinclination on her part to have any remedy tried. I now decided on bleeding her freely, which I had hesitated to do previously, from the apparent great exhaustion and the consideration that I might hasten gangrene by weakening the powers of life; I accordingly opened a vein in the arm, and when about twelve ounces had flown, perfect syncope occurred; I heard a slight gurgling, and with gentle taxis the whole contents of the sac were returned into the cavity of the abdomen. A full dose of castor oil was given as soon as the state of collapse succeeding had been removed by slight stimuli; this being rejected, I administered other aperients, which moved the bowels in about four or five hours, and she went on well from this time with scarcely any symptoms requiring treatment.

The only point of interest perhaps in this case may be the long period of incarceration of the contents of the sac (nearly seven days), together with the absence of adhesions, which would have been expected from the continued inflammation, and its publication may serve to illustrate the difficulty surgeons sometimes have in deciding on the exact time of giving up measures for reducing strangulated hernia, and having immediate recourse to an operation. It is now well understood that the earlier we operate the better, but the above detail may serve to show to what a period such symptoms may go on without the death of the patient. Had any medical friend accompanied me on my first attendance, I shquld have been inclined to operate at once, being satisfied that no delay should ever occur in relieving symptoms so urgent, and when other remedies fail, harm is done by the loss of time. Baron Larrey mentions a case in which death occurred in two hours from the strangulation; and Mr. Hey two cases where the disease proved fatal in about twenty-four hours. In this case the usual symptoms which point out its immediate necessity were present, but the unintentional delay most probably saved the patient a painful and dangerous operation, which, under the circumstances, held out few prospects of recovery.

It may seem strange to some of your readers the long delay in my being called into the patient, which may be explained by the circumstance of her living with a bedridden sister between two or three miles from my residence, and the neighbours being ignorant of and indifferent to her state.

\section{DIAGNOSIS OF CHOLERA.}

\section{TO THE EDITORS OF THE PROVINCIAL MEDICAL} JOURNAL.

Gentlbmen,-In conformity with the intention expressed in my letter of the lst inst., I now proceed to a more detailed account of some of the statements therein contained. In doing this, I will deviate so far from the ordinary course pursued in medical writings as to reserve till the last what $I$ have to add on the origin or causation of the disease; my reason for so doing being the conviction that, in a disease so anomalous, it is not only legitimate to disregard established usage, but further, when the more peculiar features have been duly discussed, much irrelevant and tedious reretition will be avoided. Feeling persuaded that enough has already been said to prove the "irreconcilable" difference between English cholera and the Asiatic or malignant disease, I shall pass at once to the examination of the first statement, which appears to call for comment-viz., "diarrhœa and vomiting may, or may not, be present."

My object in pointedly making the above assertion was to convey the idea that, although of almost universal occurrence at one or other period of the disease, diarrhœa and vomiting do not act the part in the production of collapse generally assigned to them; and also to lead to the more important conclusion, that the practitioner who rests satisfied with arresting them has performed but a portion of his duty. To this it will be necessary to revert when considering the treatment. In confirmation of the foregoing statement, I have at this moment in my recollection three cases, wherein the patients were in the state of collapse within an hour of the first feeling of indisposition, and where neither diarrhœa nor vomiting had preceded such condition, although these symptoms in their least equivocal form supervened. Again, if we regard the character of the matter discharged, of what do we find it to consist? Certainly not of the matters usually met with in English cholera, or dysentery, but, on the contrary, of the soluble parts of the blood blended with the secretion proper to the intestinal canal, in a state of partial solution and partial coagulation, to the presence of which (mucus) the term rice-water has been not inaptly given. That the immense discharges are, in reality, derived from the source above mentioned will be self-evident, when we arrive at the consideration of the state of the circulation, whether we regard the condition of the blood met with in the vessels, or that abstracted from the body during life. There is yet another peculiarity connected with the diarrhœa, which is the immense force with which the discharge is effected, and which seems to depend on the violent or spasmodic contraction of the muscular apparatus of the intestines, and the total inability of the sphincter to counteract it. This must have been observed by every man who has had the opportunity of seeing the disease, and, in confirmation of its truth, I would particularly advert to my own case. The same remark to a certain extent applies to the vomiting.

I shall now notice the suppression of the secretions of the liver and kidneys, not that this may be next in importance, but because it is more immediately connected with the natural functions, and forms a most prominent diagnostic feature in the disease. That this symptom is to be regarded in the light mentioned does not admit of question, as every man who has practical knowledge of the disease can testify. It only, therefore, is necessary for me to explain a little more fully a remark already made-viz, that this suppression of the secretions of two such important organs is universally present, and that it arises from their inability "to act upon the morbid fluid circulating through them." That this suppression is actually what its name implies, has been most abundantly proved by post-mortem investigations, the almost invariable result of which has been the totally empty and collapsed state both of the gall and urinary bladders. To this there is, however, ane 